\title{
Study and Numerical Analysis of Compressor Transition Duct
}

\author{
Beena D. Baloni, Kadiyam Vijay Kumar, S. A. Channiwala \\ Department of Mechanical Engineering SVNIT \\ Surat, Gujarat-395007, India \\ pbr@med.svnit.ac.in; kadiyam.vijay@gmail.com; sac@med.svnit.ac.in
}

\begin{abstract}
In the modern age of aviation, turbofan engines are designed with pressure ratio as high as 40 and by-pass ratios in excess of 8. Multi spool compressor connected with a transition duct fulfils the requirement of high pressure ratio. The inter-stage annular Sshaped transition duct connects the exit of LP compressor to the inlet of HP compressor. Due to the curvature of the duct, turbulence losses and flow separation losses will develop inside the duct. Sometimes, struts are placed inside the duct for better guidance of flow. The present paper incorporates numerical analysis of the compressor transition duct with CFD software ANSYS 15. The S-Shaped compressor transition duct is designed for the 3 stage LP compressor, which operates at mass flow rate $77.8 \mathrm{~kg} / \mathrm{sec}$ and pressure ratio 3.3. Numerical work consists of flow analysis of the 2D duct, the 3D duct, and the 3D duct with provision of struts. Modeling and flow analysis of the S-shaped duct is carried out with ANSYS 15.0. The results suggest that the total pressure loss is increased from 2D to $3 \mathrm{D}$ and $3 \mathrm{D}$ without strut to cases of 3D duct with struts.
\end{abstract}

Keywords: Multi spool compressor, Transition S-shaped duct, Numerical flow analysis

\section{Nomenclature}

A Area of cross-section

$\mathrm{C}_{\mathrm{P}}$ Pressure co-efficient

$\mathrm{V}_{\mathrm{a}} \quad$ Axial velocity

$\mathrm{V}_{\mathrm{w}} \quad$ Relative velocity

$\mathrm{V}_{\mathrm{u}} \quad$ Whirl velocity

h Duct height

L Axial length of the duct

M Mach number

p Static pressure

$\mathrm{p}_{0} \quad$ Total pressure

q Dynamic head

r Radius

$\mathrm{R}$ Radius of curvature

$\mathrm{T} \quad$ Static temperature

$\mathrm{T}_{0} \quad$ Total temperature

$\mathrm{U}$ Blade mean velocity

$\Delta \mathrm{C}_{\mathrm{P}}$ Pressure co-efficient difference

\section{Abbreviation}

AR Area ratio

\author{
HTR Hub to tip ratio \\ LP Low pressure \\ MRR Mean radius ratio \\ NDL Non dimensional length \\ Greek symbol \\ $\alpha \quad$ Air angle \\ $\beta \quad$ Blade angle \\ $\psi \quad$ Stage loading \\ $\lambda$ Total pressure loss \\ $\eta \quad$ Efficiency \\ $\gamma \quad$ Ratio of specific heat \\ Suffix \\ i inner wall (hub) \\ in Inlet \\ out Outlet \\ $\mathrm{m}$ mean \\ 1 Rotor inlet \\ 2 Rotor outlet \\ 3 Stator outlet \\ o Outer wall (casing)
}

\section{Introduction}

The aim of the civil aviators is to reduce the operating cost. The operating cost of the aircraft is mainly depending on the efficiency and specific fuel consumption of the engine. The efficiency increases and the specific fuel consumption decreases as the compressor pressure ratio increases. Therefore, the modern aircraft gas turbine engine is having the high pressure ratio up to 40 . The required pressure ratio is achieved by having multi-spool compressor, namely low pressure compressor (LPC) and high pressure compressor (HPC). The compressor transition duct is used to connect the LPC and 
HPC. Inter-compressor ducts normally have a reduction in mean line radius and an accelerating flow [1]. An annular Sshaped duct is an aerodynamic passage, used to redirect a fluid from one radial position to another without significantly altering the flow direction. To reduce the weight, one can minimize the effective length of the transition duct. This leads to increase losses in the duct, by increasing the change in the mean radius of the passage area. To reduce the transition losses, the duct design must be optimized without producing more weight penalty.

Over the passage of time, researchers are trying to design the duct which is having less length and weight [4, 6-10]. The total pressure loss occurs at the bottom wall more than the casing wall due to instability [8]. Performance of the duct depends on operating conditions of the outlet guide vanes of a compressor [9]. Bansod et al. [11], and Taylor et al. [12], observed the swirl development in both circular and non-circular geometries. The first observation was the swirl flow development in the second bend still retains a distinctive symmetrical and second observation was the core flow in S-duct move towards the outside wall of the first bend and exits near the inside wall of the second bend. In a circular cross sectioned S-duct diffuser, flow separation results in a comparatively large pair of contra-rotating stream-wise vortices, which occupy about a third to a half of the S-duct exit area. Such problems were investigated by many researcher [13-15] for circular cross sectioned diffusers. Hak et al. [16] and Lin [17] discussed separation flow control in a review. The flow control devices are placed on the side walls of the S-duct and slightly upstream of the separation point.

The present work incorporates numerical analysis of the compressor transition duct for 2D axi-symmetric, 3D duct, 3D duct with 4, 6 and 8 struts. The main objective is to evaluate a total pressure loss within the duct. To carry out numerical simulation, modeling of fluid domains are done with ANSYS 15.0. Whilst, flow analysis is carried out with FLUENT 15.0.

\section{Numerical Analysis}

The main objective of present work is to study the flow phenomenon and pressure loss inside the compressor transit sshaped duct with numerical analysis. The outlet conditions of the LP compressor must be known to check the performance of the compressor duct. Therefore, a 3 stage LP compressor is designed based on available, theoretical and fundamental correlations for the mass flow rate of $77.8 \mathrm{~kg} / \mathrm{s}$ and, a pressure ratio 3.3 [2,3]. Sea level conditions are considered for the initial design of the compressor. The design details and stage parameters are listed out in Table 1 and Table 2.

Table 1: Design details of LP compressor.

\begin{tabular}{|l|c|c|}
\hline Design Parameters & Inlet & Outlet \\
\hline Hub radius, $\mathrm{m}$ & 0.241 & 0.292 \\
\hline Tip radius, $\mathrm{m}$ & 0.415 & 0.364 \\
\hline Hub tip ratio & 0.58 & 0.80 \\
\hline Mean radius, $\mathrm{m}$ & 0.328 & 0.323 \\
\hline Mean velocity, m/s & 300 & 300 \\
\hline Total pressure, bar & 1.01325 & 3.34373 \\
\hline Static pressure, bar & 0.74645 & 2.72048 \\
\hline Total temperature, $\mathrm{K}$ & 288 & 420.7 \\
\hline Static temperature, K & 263.9 & 396.6 \\
\hline Density, kg/ m & 0.985 & 2.39 \\
\hline Axial velocity, $\mathrm{m} / \mathrm{s}$ & 220 & 220 \\
\hline Mach number & 0.675 & 0.551 \\
\hline
\end{tabular}


Table 2: Stage calculations of the LP compressor.

\begin{tabular}{|l|c|c|c|}
\hline Parameters & $\begin{array}{c}\text { I- } \\
\text { stage }\end{array}$ & $\begin{array}{c}\text { II- } \\
\text { stage }\end{array}$ & $\begin{array}{c}\text { III- } \\
\text { stage }\end{array}$ \\
\hline$\alpha_{1}$, Degree & 0 & 5.74 & 18.8 \\
\hline$\alpha_{2}$, Degree & 33.79 & 40.5 & 45.65 \\
\hline$\beta_{1}$, Degree & 53.75 & 51.63 & 45.65 \\
\hline$\beta_{2}$, Degree & 45.7 & 27 & 18.80 \\
\hline De-haller Number & 0.72 & 0.696 & 0.783 \\
\hline Diffusion factor & 0.49 & 0.45 & 0.31 \\
\hline
\end{tabular}

Based on compressor design data, the S- shape duct is designed by using the spline curve having the controlling point and by using half angle method $[6,7]$. The design method assumes that the variation of an inner wall radius $\left(\mathrm{r}_{\mathrm{i}}\right)$ with nondimensional axial position $(\mathrm{x} / \mathrm{L})$ and is given by Eq. 1. By maintaining the constant area of the duct values of casing wall will be calculated.

$$
r_{i}=a_{1}+a_{2} \cos \left(\pi \frac{x}{L}\right)-a_{3} \sin ^{2}\left(\pi \frac{x}{L}\right)
$$

The design dimensions and non-dimensional parameters are represented in Table 3 and Table 4.

Table 3: Geometry details of the S-shaped duct.

\begin{tabular}{|c|c|c|}
\hline Geometrical Parameters & Duct Inlet & Duct Exit \\
\hline $\mathrm{r}_{\mathrm{i}} \mathrm{m}$ & 0.285 & 0.212 \\
\hline $\mathrm{r}_{\mathrm{o}}, \mathrm{m}$ & 0.356 & 0.301 \\
\hline $\mathrm{R}_{\mathrm{m}}, \mathrm{m}$ & 0.32 & 0.256 \\
\hline $\mathrm{h}, \mathrm{m}$ & 0.071 & 0.089 \\
\hline $\mathrm{A}, \mathrm{m}^{2}$ & 0.143 & 0.143 \\
\hline $\mathrm{HTR}$ & 0.800 & 0.704 \\
\hline \multicolumn{2}{|l}{} \\
\hline
\end{tabular}

Table 4: Non-dimensional parameters of the S-shaped duct.

\begin{tabular}{|l|l|}
\hline Parameters & Value \\
\hline Area ratio, $\left(A_{\text {out }} / A_{\text {in }}\right)$ & 1 \\
\hline Non-dimensional length, $\left(h_{\text {in }} / L\right)$ & 0.294 \\
\hline Radial offset to axial length ratio, $(\Delta R / L)$ & 0.265 \\
\hline $\begin{array}{l}\text { Mean radius to the passage height at inlet, } \\
\left(R_{\text {in }} / h_{\text {in }}\right)\end{array}$ & 4.5 \\
\hline
\end{tabular}

2D axi-symmetric duct fluid domain is generated with ANSYS 15 based on the obtained duct design parameters. The axial length of the duct is considered as $241.8 \mathrm{~mm}$. The Schematic diagram for the same is depicted in Fig. 1. Nondimensional axial length (x/L) of the duct is zero at an inlet and one at the end. The bottom wall of the duct is denoted as a hub and upper wall as a casing. To get rid of the effect of inlet and outlet conditions, flow fluid domain is extended before the duct inlet and after the duct outlet. Meshing is carried out in ICEM. The bias factor is considered near walls to get a clear vision of flow. 


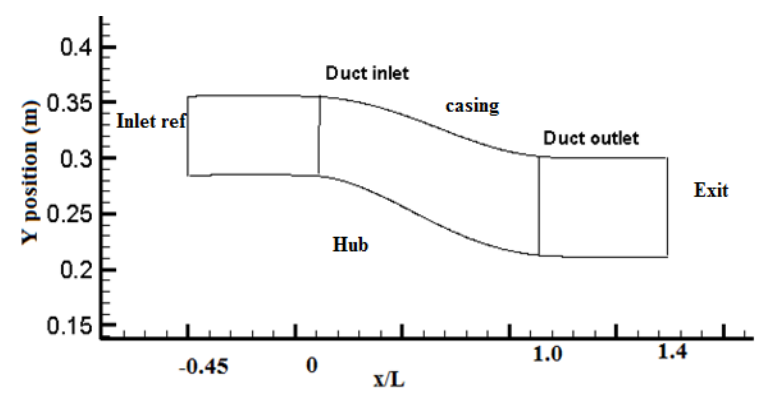

Fig. 1: Fluid domain of the 2D axi-symmetric duct.

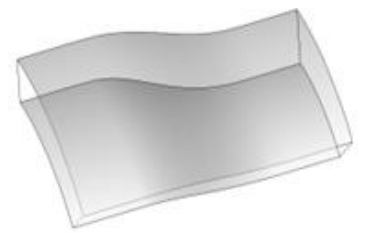

a) Without strut

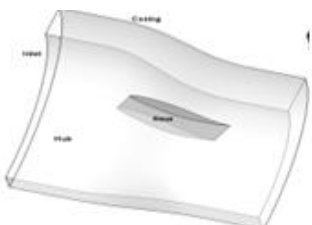

b) With 4 struts

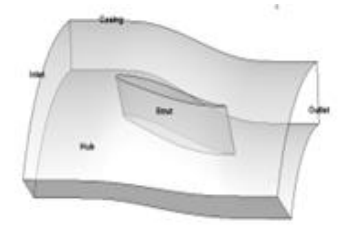

c) With 6 struts

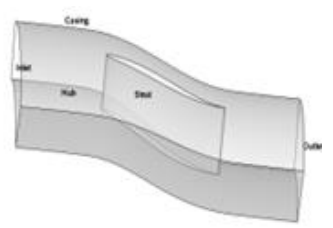

d) With 8 strut

Fig. 2: Fluid domains of the 3D duct.

For better accuracy, the analysis is further proceeded with the 3D duct. For maintaining uniform flow and reducing the flow separation struts are placed inside the duct which is limited to max 10 struts [4]. The 2D surface of the S-shape duct revolved into $360^{\circ}$, for the development of 3D geometry of an annular S-shaped transition duct. To reduce the computational time, symmetric planes are created. To analyze flow within 3D duct with struts, NACA ' 6 ' series is chosen as they belong to the low drag family [4]. 3D duct with 4 struts, 6 struts and 8 struts are selected for analysis. Strut is placed in the middle of the duct. Geometries are developed periodic rotationally. For that symmetry planes are developed according to the number of struts and shown in Fig. 2. The mesh size of 3D duct cases, are justified with an orthogonal quality of mesh. For every case the orthogonal quality is nearly 1.

Flow simulation is carried out with density base solver in FLUENT 15.0. Pressure inlet and pressure outlet is taken as inlet and outlet boundary condition respectively. For 2D analysis Spalart-Allmaras and standard k- $\varepsilon$ turbulence model is considered for $2 \mathrm{D}$ and 3D analysis respectively. Density of fluid is defined with ideal gas. Energy and momentum equations are solved up to $1 \times 10^{-05}$ residual. After convergence, in part of the post processing simulation results are discussed in terms of static pressure, total pressure, velocity magnitude and the Mach number.

\section{Results and Discussions}

Analysis of 2D and 3D compressor S-shaped transition duct simulation results are done with FLUENT 15 and Tecplot 360. For 2D duct simulation results at different axial locations from an inlet to an outlet of the duct are analyzed with the contour graph. Axial planes are created at $25 \%, 50 \%$ and $75 \%$ of duct length perpendicular to the axis of the duct. The property variations are plotted in the X-Y plot, $\mathrm{X}$-axis represents the respective parameter and y-axis represents the duct height. Meridional planes are created at $25 \%, 50 \%$ and $75 \%$ of duct height to visualize the flow along the length of the duct. The property variations are plotted in the $\mathrm{X}-\mathrm{Y}$ plot here, $\mathrm{x}$-axis represents non-dimensional axial length and $\mathrm{y}$-axis represents the respective parameter. 

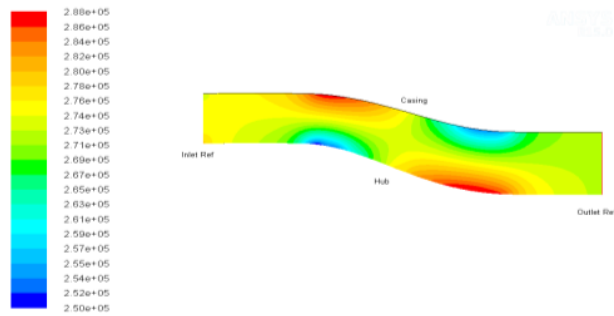

Fig. 3: Static pressure variations in the $2 \mathrm{D}$ duct.

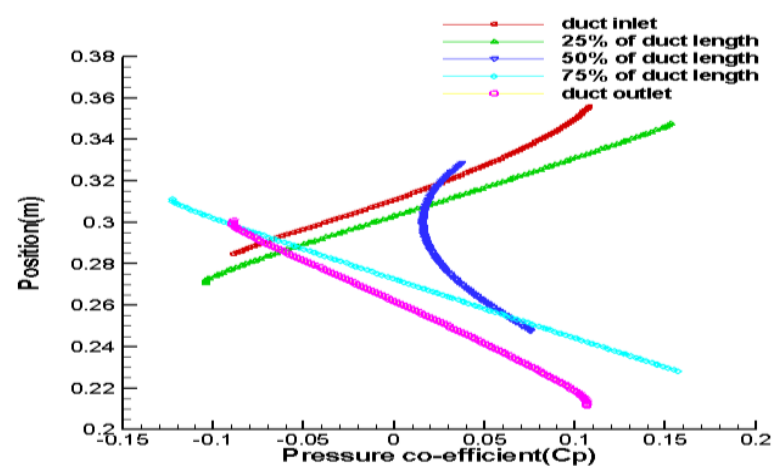

Fig. 4: Pressure co-efficient variations along duct height at different axial locations.

The static pressure contours are shown in Fig. 3. One can observe low pressure contours near the concave curvature of hub and high pressure near the convex curvature of hub. Whereas; a reverse phenomenon is observed at casing wall side as the flow is returned to the axial direction. The low pressure regions near the wall is an indication of higher kinetic energy of flow. The pressure coefficient $(\mathrm{Cp})$ variations along the duct height, at different axial planes, are depicted in Fig. 4. Pressure co-efficient $(\mathrm{Cp})$ represents the ratio between the difference between local pressure and mean static pressure at an inlet to the inlet dynamic head. The figure reveals that the nature of the pressure curve is increasing along the duct height for an inlet and $25 \%$ of duct length whereas; decreasing along the duct height for an outlet and $75 \%$ of duct length. At mid of duct length i.e. $50 \%$ the pressure is the maximum at the centre and reduced as flow moves from the centre towards duct walls. The duct shape is the reason behind this nature of the pressure curve. To get a better idea of flow velocity variations are plotted on XY plot along the height of the duct at different axial locations. Velocity profile at different axial locations (Refer: Fig. 5) reveals that velocity near the wall is zero. However, the peak of velocity profile is changes as we move from an inlet towards an outlet of the duct. The peak of velocity is lying near hub, at the middle and near tip (casing wall) of the duct near an inlet, the middle and near outlet respectively.

In the present work, total pressure loss and pressure recovery coefficient are chosen as a performance parameters. The variations in total pressure is plotted in the XY plot at hub and tip of the duct as shown in Fig. 6. Near hub, profile the total pressure is decreased in concave curvature from $305000 \mathrm{~Pa}$ to $294000 \mathrm{~Pa}$ in first half of the duct axial length. Whereas; further gain, in convex curvature $294000 \mathrm{~Pa}$ to $304000 \mathrm{~Pa}$, is observed from approximately middle length to $75 \%$ of the duct axial length (Refer: Fig. 6). The mass weighted average of total pressure at the duct inlet is 333717.28Pa and at duct outlet is $332739.72 \mathrm{~Pa}$ which indicates $1.768 \%$ loss in total pressure. 


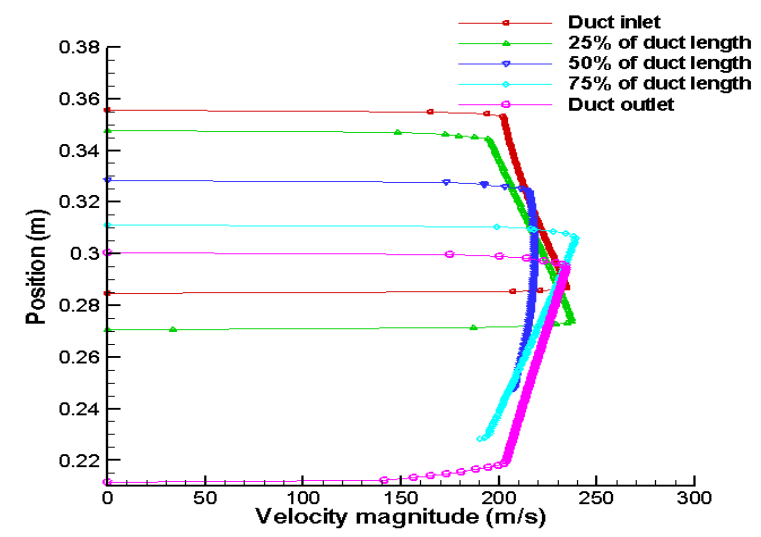

Fig. 5: Velocity variations along duct height at different axial locations.

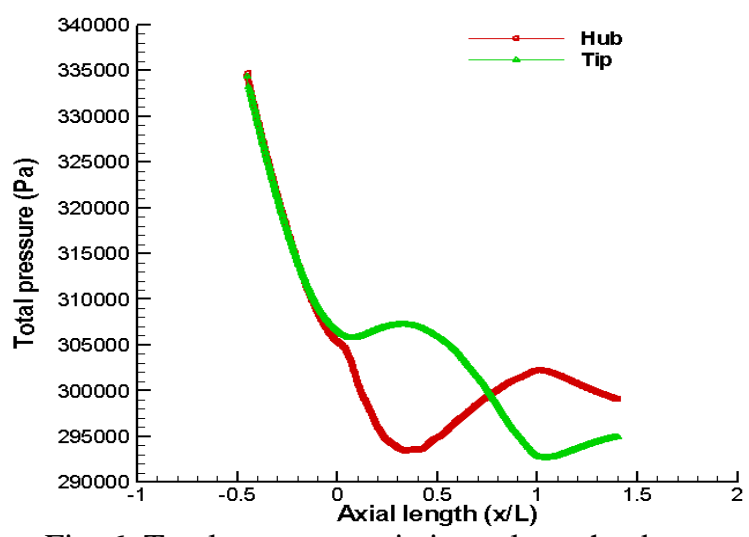

Fig. 6: Total pressure variations along the duct.

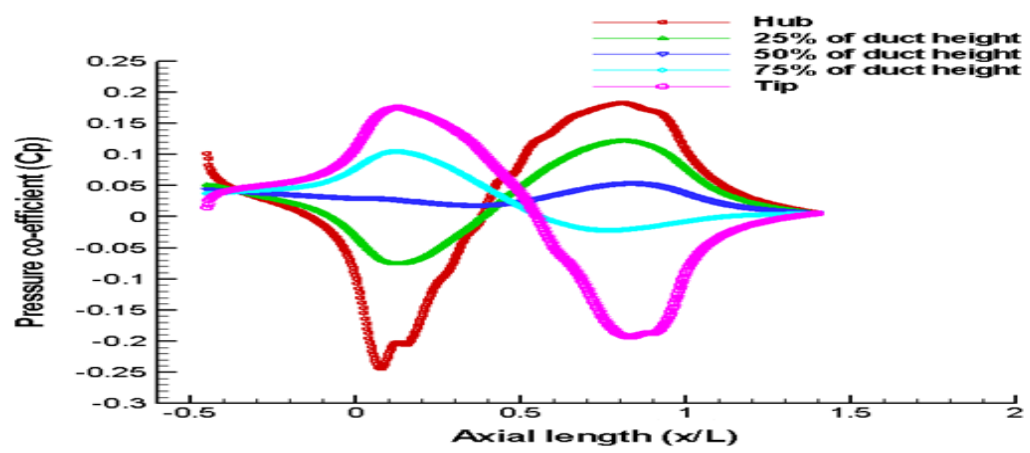

Fig. 7: Pressure co-efficient variations along the duct length for the different Meridional plane.

The variations of $\mathrm{Cp}$, along the duct length for the different meridional plane, is same as static pressure variations as shown in Fig. 7. Flow along the hub is subjected to adverse pressure gradient as $C_{p}$ increases from -0.245 to +0.17 from approximately $28 \%$ to $70 \%$ of the duct length. Near the tip i.e. casing wall $\mathrm{C}_{\mathrm{p}}$ is reduced from +0.165 to -0.2 along similar length. These gradients are varying significantly across the duct height for different meridional planes. The $5.518 \%$ mass flow rate deviation is observed in the 2- $\mathrm{D}$ simulation results compare to theoretical design value.

After satisfactory analysis of the 2D duct, 3D analysis of fluid domain is carried out without strut and with 4, 6, and, 8 number of struts. These studies are performed to get an idea of the change in flow behavior and pressure loss from $2 \mathrm{D}$ to $3 \mathrm{D}$ as well as the duct without strut and with a different number of struts. For visualization of flow, some axial planes are 
created between duct inlet and duct outlet. Duct inlet plane and duct outlet plane is located at $135 \mathrm{~mm}$ and at $350 \mathrm{~mm}$ from the inlet reference respectively. In case of 3D duct without strut, 3 axial planes are created at $25 \%, 50 \%$, and $75 \%$ axial length between inlet and outlet planes. Whereas; 4 axial planes are created at $25 \%, 50 \%$, and $75 \%$ and $90 \%$ of the strut chord.

The variations of static pressure for different axial planes, duct inlet and duct outlet are shown in the Fig. 8. The pressure is going to increase near the casing from duct inlet to plane 2 and from the plane 2 to duct outlet it is going to decrease. The variation trend is similar to $2 \mathrm{D}$ simulation results. In case of struts inside the duct, from the leading edge of strut to the tailing edge of the strut area is increased and followed by decreases. The maximum area of the strut is at the second plane from an inlet plane.
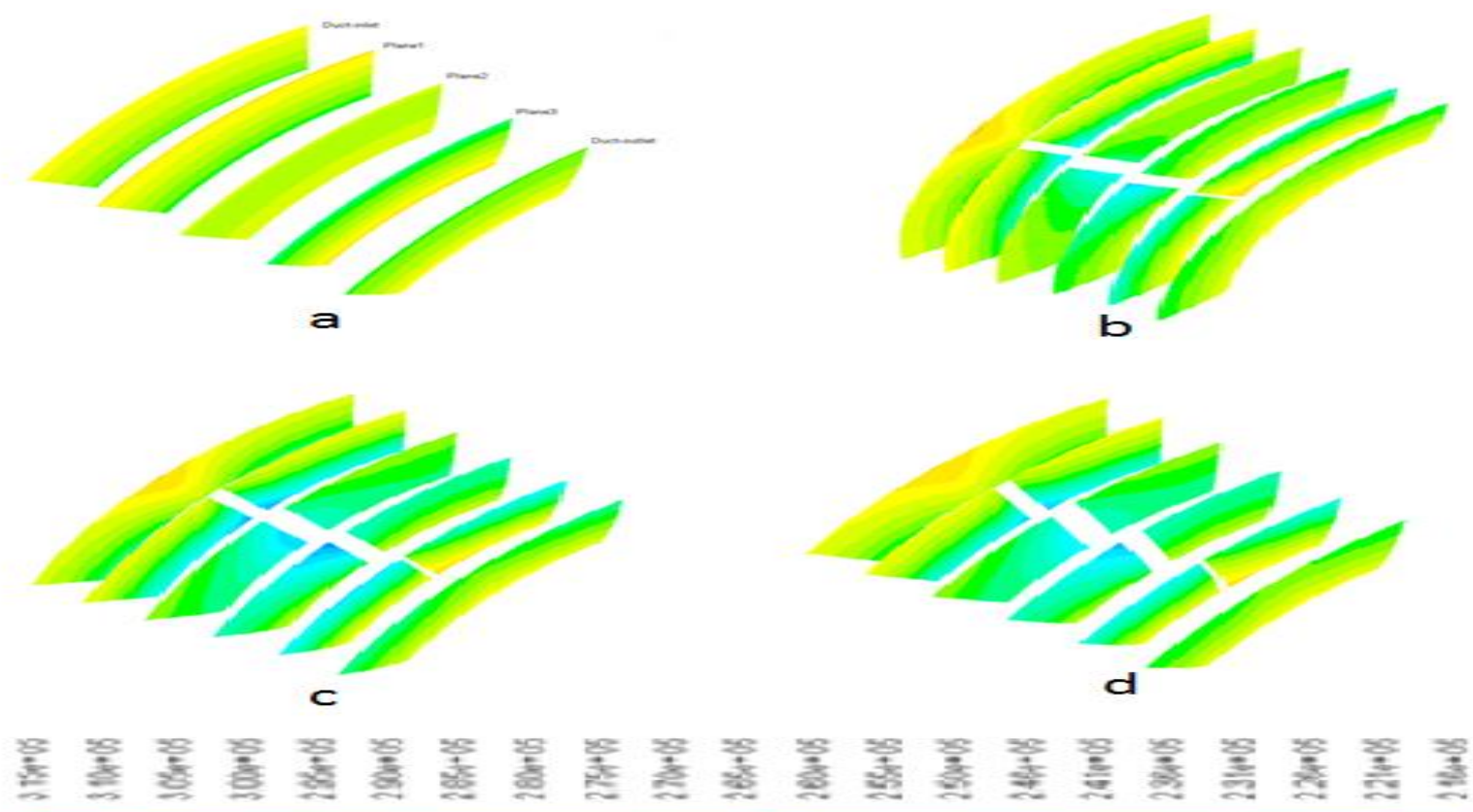

Fig. 8: Static pressure contours at different axial planes of 3D duct without and with struts. a) Without strut b) 4 strut c) 6 strut d) 8 strut. 

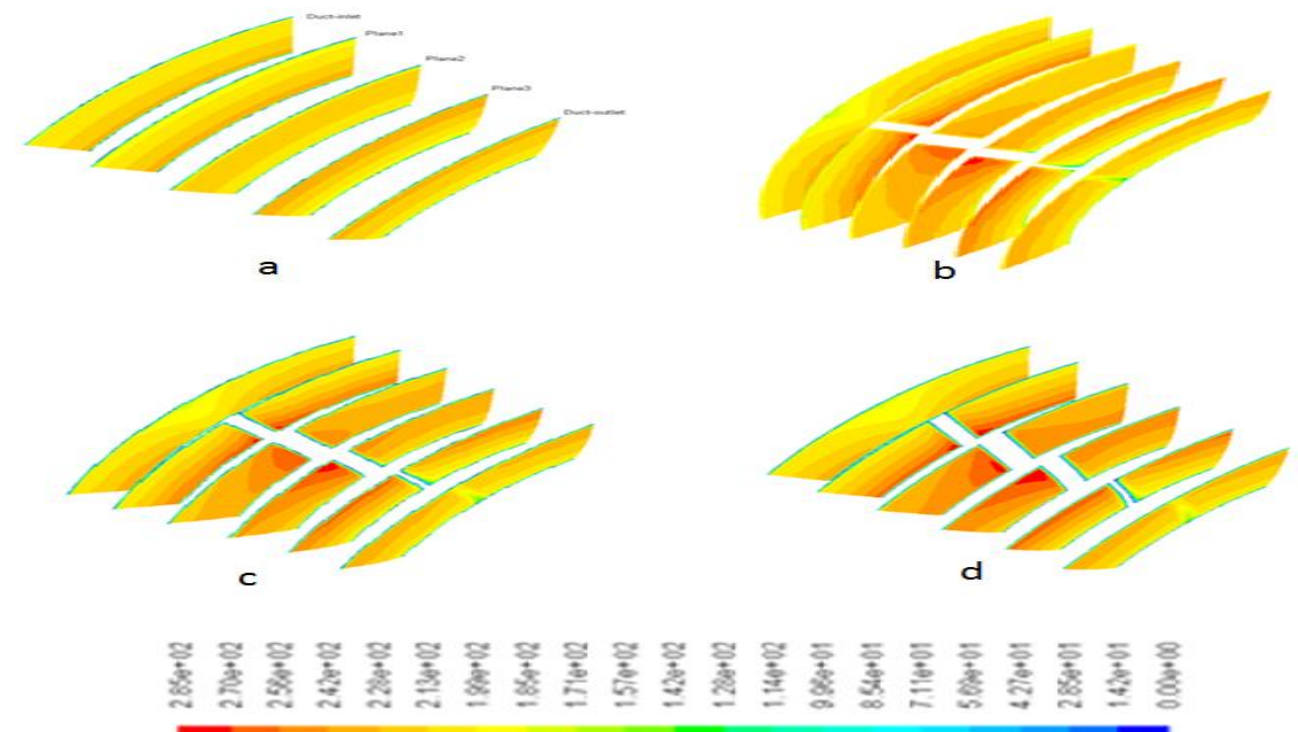

Fig. 9: Velocity contours at different axial planes of the 3D duct without and with struts. a) Without strut b) 4 strut c) 6 strut d) 8 strut.

Near the hub the pressure variation is decreased from duct inlet to plan1, from plane1 to duct outlet it is going to increase for all four cases. When struts placed inside of the duct, near the strut surface static pressure is going to decrease. With an increase in the strut number, flow gets disturbed near the struts surface and static pressure is going to decrease as shown in the Fig. 8. Flow passage area is decreases with an increase in number of struts from without strut case to with strut cases. The low pressure contours are mainly observed at the pressure surface of strut near the hub of the first plane from an inlet; and near casing at the rest of the planes, excluding an inlet and outlet plane. These low pressure regions are less at the suction surface of strut in the case of four struts compared to other cases with strut.

Figure 9 represents velocity variations at different axial planes. Maximum velocity develops near the casing wall side of the third plane from an inlet plane. As the flow area decreases from the duct inlet towards the second plane from an inlet plane due to strut aerofoil shape, velocity magnitude is increases. Compare to suction side, high velocity contours are observed near the pressure side of strut. Both static pressure and velocity contours suggest that an inclusion of strut leads to more non-uniformity of flow within the duct. These non-uniformity increases with an increase in number of strut.

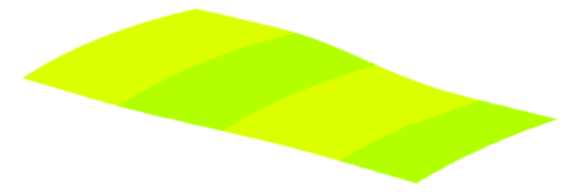

a

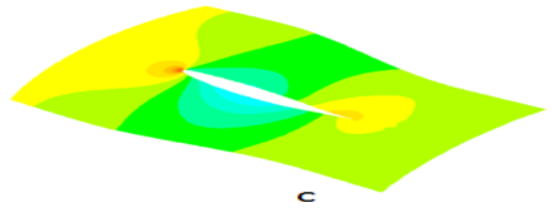

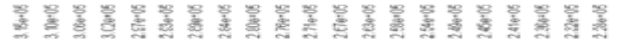

Fig. 10: Static pressure variations on the mean meridional plane at $50 \%$ of duct height. a) Without strut b) 4 strut c) 6 strut d) 8 strut
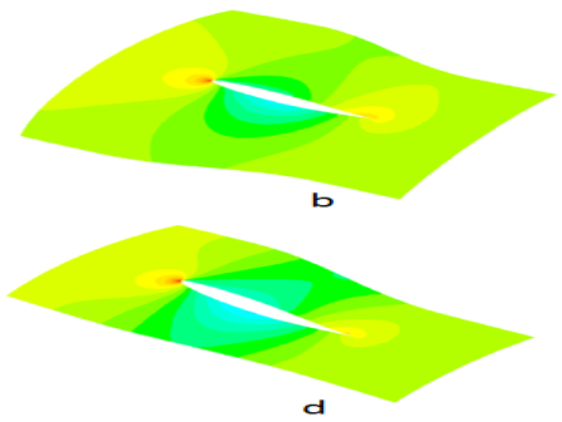
Table 5: Summary of simulation results for the 2D and 3D duct.

\begin{tabular}{|l|c|c|c|c|c|}
\hline \multirow{2}{*}{ Parameter } & 2D & \multicolumn{4}{|c|}{ 3D duct } \\
\cline { 3 - 6 } & duct & Without strut & With 4 struts & With 6 struts & With 8 struts \\
\hline Mass flow rate $(\mathrm{kg} / \mathrm{s})$ & 73.51 & 73.04 & 73.08 & 72.8 & 72.4 \\
\hline Inlet Density $\left(\mathrm{kg} / \mathrm{m}^{3}\right)$ & 2.39 & 2.41 & 2.40 & 2.41 & 2.41 \\
\hline Inlet Mach number & 0.54 & 0.53 & 0.53 & 0.53 & 0.53 \\
\hline Total Pressure loss $(\%)$ & 1.768 & 2.198 & 3.2129 & 3.7525 & 4.8 \\
\hline
\end{tabular}

To get more idea about the effect of strut inclusion, pressure contours are plotted at $50 \%$ of duct height on the mean meridional plane for cases of the duct without and with struts as shown in the Fig. 10. Uniform distribution of pressure counters at angular locations of the symmetry plane are observed in the case of the duct without struts. As we provide a different number of struts inside the duct passages, one can observe the clear effect of strut profile. The high pressure contour near LE of strut is an indication of stagnant flow at these regions in all the cases of struts. The figure reveals that as we increase the number of struts inside the duct, an area occupied by comparatively low pressure contours are increased on both surfaces of strut. The nature of flow indicates that for the present case, as we increase the number of strut there is a reduction in flow area. The flow is also obstructed by an inclusion of strut which led towards the high velocity and low pressure regions near strut surfaces. At TE of strut again pressure is increased in all cases of struts.

The compiled simulated results are listed in Table 5 for all the cases. As mentioned earlier, the theoretical design mass flow rate, density and the Mach number at outlet of the compressor are $77.8 \mathrm{~kg} / \mathrm{s}, 2.39 \mathrm{~kg} / \mathrm{m}^{3}$ and 0.551 respectively. The simulation results suggests maximum $6.9 \%, 0.8 \%$ and $3.8 \%$ variations from theoretical design values of Mach number, density and Mach number respectively. The minimum pressure loss of $1.768 \%$ in terms of inlet dynamic head observed in case of 2D simulation. Whereas; this loss is increasing from 2D to 3D simulation cases. As we increase the number of struts the pressure loss inside the duct is also increases. Maximum 4.8\% pressure loss occurs inside the duct passage with 8 struts for the present compressor duct.

\section{Conclusions}

Numerical analysis of the 2D and 3D compressor transition duct with and without struts is carried out. The following conclusions are made based on flow analysis of different flow properties, performance parameters of duct and deviation of simulation results from theoretical design values.

- Exit conditions of the designed LP compressor are compared with simulation results of the S-shaped duct at an inlet as maximum $6.9 \%$ deviation is observed in case of mass flow rate.

- Flow non- uniformity within the duct is increasing with the increase in number of strut for present the 3D compressor transition duct.

- Minimum total pressure loss occurs in 2D axi-symmetry i.e. $1.78 \%$, in terms of inlet dynamic pressure head. For 3D transition duct of present LP compressor, the pressure loss increases with an increase in number of strut.

\section{References}

[1] P. Walsh \& P. Fleture, "Gas Turbine-performance," Blackwell Science Limited, vol. 5, pp.215-224, 1998.

[2] H. I. H. Saravanamuttoo, Henry Cohen, G. F. C. Rogers, PV Straznicky, "Gas Turbine Theory," Pearson education limited, 6th ed, vol. 5, 2009.

[3] A. F. EI-Sayed, Aircraft propulsion and Gas Turbine Engines. CRC press, Taylor \& Francis group, 2008.

[4] D. Bailey, "The aerodynamic performance of an annular S-shaped duct,"Ph.D. Thesis, Loughborogh University, 1977.

[5] K. Britchfond, "The aerodynamic behavior of annular S-shaped duct," Ph.D. Thesis, Loughborogh University, 1998.

[6] D. Ortiz, R. Miller, H. P. Hodson, J. P. Longley, "Effect of length on compressor inter-stage duct performance," GT2007-27752, ASME Technical Paper, 2007. 
[7] S. R. Wellborn, B. A Reichert, "An Experimental Investigation Of The Flow In A Diffusing S-Duct," ASME, SAE, AIAA 93-0018, 1992.

[8] H. Lu, X. Zheng, "A combinatorial optimization design method applied to S-shaped compressor transition duct design," J Aerospace engineering, pp. 1749-1758, 2014.

[9] E. M.J. Naylor, O. Duenas, "Optimization of non-axisymmetric End walls in compressor S-shaped ducts," Journal of tubomachinary, vol. 132, no. 1, p. 011011, 2010.

[10] J. Donghai, L. Xiwu, "Optimization of end wall contouring in axial compressor S-shaped ducts," Chinese Journal of Aeronautics,vol. 28, no. 4, pp. 1076-1086, 2015.

[11] B. Bansod, P. Bradshaw, "The flow in S-shaped ducts," Journal of Aeronautical, vol. 23, pp. 131-140, 1972.

[12] A. M. K. P.Taylor, J. H. Whitelaw, M. Yianneskis, "Curved Ducts with Strong Secondary Motion: Velocity Measurements of Developing Laminar and Turbulent Flow," Journal of Fluids Engineering, vol. 104, pp. 350-359, 1982.

[13] J. H. Whitelaw, S. C. M. Yu, "Turbulent flow characteristics in an S-shaped diffusing duct," Flow Measurement \& Instrument, vol. 4, no. 3, pp. 171-179, 1993.

[14] S. C. M. Yu, E. L. Goldsmith, "Some aspects of the flow in S-shaped diffusing ducts," Aeronaut J, vol. 98, no. 978, pp. 305-310, 1994.

[15] B. H. Anderson, D. R. Reddy, K. Kapoor, "Study on computing separating flows within a diffusing inlet S-duct," $J$ Propul Power, vol. 10, no. 5, pp. 661-667, 1994.

[16] M. Gad-el-Hak, D. M. Bushnell, "Separation control: review," Journal of Fluids Engineering, vol. 113, no. 1, pp. 530, 1991.

[17] J. C. Lin, "Review of research on low-profile vortex generators to control boundary-layer separation," Progress in Aerospace Sciences, vol. 38, pp. 389-420, 2002. 